\title{
Controle da ferrugem e da broca-dos-ramos da figueira com diferentes fungicidas e inseticidas
}

\author{
Éder Júnior Mezzalira ${ }^{1}$,André Luiz Piva ${ }^{1}$, Gilmar Antônio Nava*2, Dalva Paulus ${ }^{3}$, Anderson Santin ${ }^{1}$ \\ http://dx.doi.org/10.1590/0034-737X201562010006
}

\begin{abstract}
RESUMO
Temperaturas e precipitações elevadas favorecem a incidência da ferrugem (Cerotelium fici (Cast.)) e da brocados-ramos (Azochis gripusalis (Walker, 1859) (Lepidoptera: Pyralidae)), limitando a produção comercial de figos. O objetivo deste trabalho foi comparar a eficiência de fungicidas e inseticidas alternativos em relação à de produtos convencionais registrados para a cultura. Foram realizados dois experimentos, no delineamento de blocos inteiramente casualizados, com quatro repetições, no setor de fruticultura da Universidade Tecnológica Federal do Paraná, Campus Dois Vizinhos. Para controle da ferrugem, foram utilizados, em $100 \mathrm{~L}$ de água, azoxistrobin (10 g), calda bordalesa ( $1.500 \mathrm{~g}$ de cal virgem $+1.500 \mathrm{~g}$ de sulfato de cobre) e testemunha (água). No controle da brocados-ramos utilizaram-se, em $100 \mathrm{~L}$ de água, azadiractina (1.000 mL P.C.), alho (Allium sativum L.) (100 mL P.C.), cinza (20.000 g), extrato de fumo (nicotina) (10.000 $\mathrm{mL}$ do preparado), deltametrina (50 mL P.C.), Bacillus thuringiensis Berliner (100 g P.C.), rotenona (1.000 mL P.C.), sabão de coco (1.000 g) e testemunha (água). A calda bordalesa foi o tratamento mais efetivo no controle da ferrugem, promovendo aumento da produtividade e da qualidade dos frutos. A deltametrina promoveu o melhor controle da broca-dos-ramos da figueira. Entre os produtos alternativos testados, o alho foi o mais efetivo no controle dessa praga.
\end{abstract}

Palavras-chave: Azochis gripusalis (Walker, 1859) (Lepidoptera: Pyralidae), Cerotelium fici Cast., figo, MIP, perdas na produção.

\section{ABSTRACT}

\section{Rust and fig tree borer control by different fungicides and insecticides}

High temperature and rainfall stimulate the attack of rust (Cerotelium fici (Cast.)) and fig tree borer (Azochis gripusalis (Walker, 1859) (Lepidoptera: Pyralidae)), limiting the commercial production of figs. The objective of this work was to compare the efficiency of alternative fungicides and insecticides with conventional products widely used in agriculture for controlling these pests. Two experiments were carried out in a completely randomized block design with four replications in the Universidade Tecnológica Federal do Paraná (Federal Technological University of Paraná), Dois Vizinhos, Paraná State, Brazil. For the rust control, azoxystrobin (10g), bordeaux mixture (1,500 g limestone $+1,500 \mathrm{~g}$ copper sulphate) was used in $100 \mathrm{~L}$ of water and control (water). For the fig tree borer control, azadirachtin (1,000g $\mathrm{mL}$ p.c.), garlic (Allium sativum L.; $100 \mathrm{~mL}$ p.c.), ashes $(20,000 \mathrm{~g})$, nicotine $(10,000 \mathrm{~mL}$ of the preparation), deltamethrin (50mL p.c.), Bacillus thuringiensis Bertiner (100 mL p.c.), rotenone (1,000mL p.c.),

\footnotetext{
Submetido em 05/03/2012 e aprovado em 19/11/2014.

${ }^{1}$ Universidade Estadual do Oeste do Paraná, Departamento de Agronomia, Marechal Cândido Rondon, Paraná, Brasil. eder.mezzalira@gmail.com; andrepv8@gmail.com; santin@ hotmail.com

${ }^{2}$ Universidade Tecnológica Federal do Paraná, Departamento de Horticultura, Dois Vizinhos, Paraná, Brasil. gilmarnava@utfpr.edu.br

${ }^{3}$ Universidade Tecnológica Federal do Paraná, Departamento de Horticultura, Dois Vizinhos, Paraná, Brasil. dalvapaulus@utfpr.edu.br

Autor para correspondência: gilmarnava@utfpr.edu.br
}

Rev. Ceres, Viçosa, v. 62, n.1, p. 044-051, jan/fev, 2015 
coconut soap $(1,000 \mathrm{~g})$ were used in $100 \mathrm{~L}$ of water and water (control). The Bordeaux mixture was the most effective treatment in controlling rust, increasing the productivity and fruit quality. Deltamethrin provided the best controlling for borer branches of the fig tree. Among the evaluated alternative products, garlic was the most effective in controlling such pest.

Key words: Azochis gripusalis (Walker, 1859) (Lepidoptera: Pyralidae), Cerotelium fici Cast., fig, MIP, yield.

\section{INTRODUÇÃO}

A figueira, Ficus carica L., pode ser cultivada em pequenas áreas e sua produção direcionada para comercialização de frutos in natura e produção de frutos verdes, visando à industrialização (Pio et al., 2007). Apresenta excelente adaptação climática, sendo cultivada em regiões subtropicais quentes e em regiões temperadas (Dalastra et al. 2009), embora seu cultivo venha sendo realizado de maneira tradicional, sem inovações ou melhorias técnicas (Giacobbo et al., 2007).

Com produção de $28.253 \mathrm{t}$ de figos em 2013, em uma área colhida de 2.814 ha, as regiões Sudeste e Sul são as maiores produtoras brasileiras da fruta, com destaque para os estados de São Paulo, Rio Grande do Sul e Minas Gerais, que respondem por mais de $90 \%$ da produção nacional (IBGE, 2015).

A ferrugem da figueira (Cerotelium fici (Cast.)), doença mais limitante à produção comercial da cultura, apresenta-se largamente difundida nas regiões produtoras do país (Pio et al., 2007). Em temperaturas superiores a $22^{\circ} \mathrm{C}$ e umidade relativa acima de $80 \%$, que favorecem seu desenvolvimento, e se não for controlada, pode causar perdas de $80 \%$ da produção (Medeiros, 2002). Os sintomas apresentados, na planta, são pequenas manchas verde-amareladas (posteriormente pardas), nas folhas; na epiderme da face abaxial formam-se massas ferrugíneas pulverulentas, com os esporos do fungo (Chalfoun \& Carvalho, 1997).

A broca-dos-ramos, Azochis gripusalis (Walker, 1859) (Lepidoptera: Pyralidae) é a principal praga do figo (Medeiros, 2002; Pio et al., 2007) e pode causar perdas de produção superiores a $30 \%$, quando não controlada corretamente (Fadini et al. 2003). A mariposa realiza as posturas sobre os ramos e folhas e as lagartas, após eclodirem dos ovos, provocam destruição da parte lenhosa interna do ramo em crescimento. À medida que a figueira se desenvolve, as folhas murcham e os frutos atrofiam-se e secam, comprometendo a produção (Medeiros, 2002). Assim, o controle dessa praga assume papel significativo para a viabilização do cultivo da figueira.
A aplicação de fungicidas é a prática mais utilizada para controle da ferrugem, com pulverizações desde o período de repouso da planta até a colheita dos frutos (Chalfoun \& Carvalho, 1997; Abrahão et al. 2002). O controle deve ser iniciado com um tratamento de inverno, que é realizado logo após a poda, utilizando-se calda sulfocálcica. Após a brotação das plantas, são realizadas pulverizações quinzenais, intercalando-se produtos à base de Mancozeb, Azoxistrobin, Hidróxido de cobre, Oxicloreto de cobre, Tebuconazole, entre outros.

Com relação à broca-dos-ramos, seu controle deve ser feito de forma integrada, associando-se os métodos culturais, físicos e químicos, como podas de frutificação e pulverizações com inseticidas fosforados (Gallo et al. 2002; Medeiros, 2002). Por outro lado, a eficiência dos inseticidas biológicos ainda necessita de comprovação científica para o controle de pragas, incluindo-se a broca dos-ramos da figueira.

Considerando-se a importância desses problemas fitossanitários para a produção comercial de figos, no Sudoeste do Paraná, principalmente por causa das características meteorológicas da região, que favorecem o surgimento e a proliferação da ferrugem e da brocados-ramos, a crescente demanda da população por figos com menor carga de agrotóxicos e a carência de pesquisas nessa área, este trabalho teve por objetivo comparar ingredientes ativos alternativos com ingredientes ativos convencionais, de fungicidas e inseticidas, para o controle dessas pragas, na região.

\section{MATERIAL E MÉTODOS}

Dois experimentos para controle da ferrugem e da broca-dos-ramos foram conduzidos, de 19 de novembro de 2009 a 16 de março de 2010, sendo os produtos utilizados descritos na (Tabela 1). Utilizou-se delineamento de blocos inteiramente casualizados, com quatro repetições. O trabalho foi realizado no setor de Fruticultura da Universidade Tecnológica Federal do Paraná Campus Dois Vizinhos, PR (latitude 2542'S, longitude $53^{\circ} 06^{\prime} W$, altitude $520 \mathrm{~m}$ ), na região Sudoeste do Paraná. O clima da região é tipo Cfa, segundo a classifi- 
cação climática de Köppen (Köppen, 1936). O pomar foi implantado com o cultivar Roxo de Valinhos, em solo Nitossolo Vermelho distroférrico típico (EmbrapaCNPS, 2006), no espaçamento de 2,0 x 5,0m e cada unidade experimental foi composta por duas plantas de nove anos de idade.

As pulverizações para controle da ferrugem foram realizadas em intervalos de 14 dias, sendo iniciadas em 20/11/2009 e encerradas em 02/03/2010, num total de 11 aplicações. Nas aplicações iniciais, foram utilizados volumes médios de calda de 500 L/ha, suficientes para bom molhamento da área foliar. Este volume foi aumentado gradativamente, conforme o incremento de área foliar das plantas, até aproximadamente $1000 \mathrm{~L} /$ ha. Os produtos foram aplicados com pulverizador costal com capacidade de $20 \mathrm{~L}$ e equipado com bico leque, modelo JSF 11004, malha 50, pressão de serviço de 30 lbf.pol ${ }^{-2}$, vazão de 1,31 L.min ${ }^{-1}$ e ângulo de aplicação de $110^{\circ}$. Nesse experimento, o controle da broca-dos-ramos também foi realizado em intervalos de 14 dias, com uso de deltametrina $(50 \mathrm{~mL}$ p.c./100 L de água), de 20/11/2009 a 12/01/2010 (14 dias antes da primeira colheita comercial), num total de cinco aplicações. A partir do início da colheita dos frutos, a Deltametrina (que tem carência de 14 dias) foi substituída pelo Natualho (100 mL/100 litros de água). Para o controle da ferrugem, no experimento 2, foi aplica$\mathrm{da}$, de forma padronizada para todas as unidades experimentais, a partir de 30/11/2009, calda bordalesa $(1,5$ $\mathrm{kg}$ de cal $+1,5 \mathrm{~kg}$ de sulfato de cobre/100 litros de água), seguindo-se os mesmos procedimentos, intervalos e término de pulverizações anteriormente descritos para o experimento 1 .

A incidência e a severidade da ferrugem nas folhas foram avaliadas em 26 de janeiro e 28 de fevereiro de
2010, respectivamente início da maturação dos frutos e pico de produção. Para a avaliação da severidade da doença, foram marcadas as dez primeiras folhas basais, em quatro ramos por planta, um em cada quadrante. O índice de severidade foi obtido utilizando-se escala diagramática, considerando-se os níveis de lesão: I sem sintomas; II: até 4,39\%; III: 4,39 a 8,88\%; IV: 8,88 a 16,00\%; V: 16,00 a 33,32\%; VI: 33,32 a 63,00\% (Lorenzetti et al. 2008).

Todos os frutos dos ramos marcados de cada unidade experimental foram colhidos e efetuou-se a contagem de todos os ramos produtivos por planta, para determinação dos componentes de rendimento (número de frutos por ramo e por planta, peso médio de frutos e produção por planta). A acidez total titulável (ATT) foi determinada com peagâmetro digital BEL W3B, a partir da titulação de $10 \mathrm{~mL}$ de suco e $90 \mathrm{~mL}$ de água destilada, com solução de $\mathrm{NaOH} 0,1 \mathrm{~N}$ até pH 8,1, sendo a acidez expressa em percentagem. Para a determinação dos sólidos solúveis totais (SST), usou-se refratômetro digital HANNA HI 96801, sendo os dados expressos em ${ }^{\circ}$ Brix.

Para as avaliações de incidência da broca-dos-ramos, realizadas em duas épocas ( 22 de janeiro e 22 de fevereiro de 2010), por meio da visualização dos danos provocados pela praga sobre os ramos e frutos, foram utilizados oito ramos, previamente identificados, sendo dois de cada quadrante da planta. Para a estimativa da produção de frutos por planta, realizou-se a contagem e a pesagem de todos os frutos dos oito ramos marcados. A produção por planta foi estimada, utilizando-se o número de ramos produtivos de cada planta. A colheita foi realizada a cada dois ou três dias, dependendo da quantidade de frutos, sendo realizada diariamente durante o período de maior produção.

Tabela 1. Produtos utilizados para o controle de ferrugem e da broca-dos-ramos da figueira "Roxo de Valinhos"

\begin{tabular}{|c|c|c|}
\hline \multicolumn{3}{|c|}{ Experimento 1- Controle de ferrugem } \\
\hline Ingrediente (s) ativo (s) & Produto comercial (P.C) & Dose P.C. (g ou mL/100 L) \\
\hline Azoxistrobin $(500 \mathrm{~g} / \mathrm{kg})$ & Amistar $500 \mathrm{WG}$ & 10 \\
\hline Hidróxido de cálcio + sulfato de cobre & Calda bordalesa ${ }^{2}$ & 1.500 \\
\hline \multicolumn{3}{|c|}{ Experimento 2- Controle da broca-dos-ramos } \\
\hline Azadiractina $(0,12 \%)$ & Neenmax & 1.000 \\
\hline Alho & Natualho & 100 \\
\hline Cinza (potássio) ${ }^{1}$ & Calda de cinza vegetal ${ }^{3}$ & 20.000 \\
\hline Fumo (Nicotina) & Extrato de fumo ${ }^{4}$ & 10.000 \\
\hline Deltametrina $(25 \mathrm{~g} / \mathrm{L})$ & Decis $25 \mathrm{EC}$ & 50 \\
\hline Bacillus thuringiensis (32 g/kg) & Dipel WP & 100 \\
\hline Rotenona & Rotenat CE & 1.000 \\
\hline Sabão & Extrato de sabão $\operatorname{coco}^{5}$ & 1.000 \\
\hline
\end{tabular}

${ }^{1}$ Potássio como principal elemento. ${ }^{2}$ Preparada pela diluição dos ingredientes em vasilhas separadas e mediante agitação constante das soluções com os ingredientes ativos durante a sua mistura e aplicação; ${ }^{3}$ Cinza oriunda da combustão de madeiras diversas em fornalha; ${ }^{4} \mathrm{Macerado}$ de $90 \mathrm{~g}$ de fumo em $1 \mathrm{~L}$ de água $+10 \mathrm{~mL}$ de álcool) diluído em 9L de água; ${ }^{5}$ Preparado com $1.000 \mathrm{~g}$ de sabão picado diluído em $100 \mathrm{~L}$ de água morna. 
As condições climáticas do entorno do pomar foram monitoradas, a partir dos dados fornecidos pela estação meteorológica do Instituto Nacional de Meteorologia (Inmet, 2010), localizada na Universidade Tecnológica Federal do Paraná, no Campus Dois Vizinhos, a cerca de $300 \mathrm{~m}$ da área experimental.

Os dados foram submetidos à análise de variância e, as médias, comparadas pelo teste de Scott-Knott $(\mathrm{p}<0,05)$, com o programa estatístico Genes (Cruz, 2006).

\section{RESULTADOS E DISCUSSÃO}

\section{Controle da ferrugem}

Maior número de frutos por ramo e por planta e produção por planta foram obtidos quando se utilizou controle da doença com calda bordalesa e azoxistrobin. A calda bordalesa promoveu maior peso médio dos frutos (Tabela 2). Esses resultados foram devidos ao melhor controle da ferrugem, pela aplicação de calda bordalesa ou azoxistrobin. A elevação das taxas de fotossíntese depende, dentre outros fatores, do máximo aproveitamento da luz disponível, o qual pode ser obtido pela manipulação cultural (Jackson, 1980; Bernardes, 1987), incluindo-se o controle fitossanitário da ferrugem, que visa à redução da abscisão e ao aumento da capacidade fotossintética foliar. A eficiência de produtos cúpricos no controle de ferrugens em plantas já foi comprovada, para diversas espécies, porém com resultados distintos entre culturas e condições meteorológicas dos locais. A calda bordalesa vem sendo usada, principalmente, por produtores alternativos ao sistema convencional de produção, por se mostrar efetiva na prevenção de várias do- enças em fruteiras, incluindo-se as ferrugens (Abrahão et al. 2002). Apresenta efeito protetor, devido ao cobre (ação de contato), e também auxilia na nutrição e na formação de barreiras de resistência, pois o $\mathrm{Cu}$ é essencial em rotas metabólicas de formação de compostos de resistência (Taiz \& Zieger, 2013). Para Carvalho (2009), tratamentos com calda bordalesa aumentaram o rendimento de frutos e reduziram significativamente a severidade da ferrugem asiática da soja, sendo que a eficiência de controle variou de 60 a $67 \%$, dependendo do cultivar. Os fungicidas oxicloreto de cobre, hidróxido de cobre e óxido cuproso, quando aplicados isoladamente, foram eficientes no controle da ferrugem da goiabeira, apresentando eficiência comparável à do tebuconazole (Goes et al., 2004).

A incidência de ferrugem foi intensa, por causa das condições favoráveis, de temperaturas, umidade do ar e precipitação elevados, à ocorrência da doença (Figura 1). Isso provocou desfolha precoce e intensa das plantas sem tratamento (testemunhas), com prejuízos ao crescimento e à qualidade dos frutos (Tabela 2), em virtude da grande quantidade de frutos e da redução da área foliar. A desfolha precoce das fruteiras reduz as reservas das plantas, por causa da menor produção de fotoassimilados, reduzindo a produtividade e a vida útil dos pomares (Alves, 2006). A calda bordalesa foi o melhor tratamento para controle da ferrugem, nas duas avaliações realizadas, seguida de azoxystrobin, sendo ambos superiores à testemunha (Tabela 2). Esse é um produto alternativo, que se mostra eficiente se aplicado preventivamente, ao passo que a azoxistrobin tem mostrado sucesso quando utilizado curativamente, já que tem ação sistêmica (Freire et al., 2006).

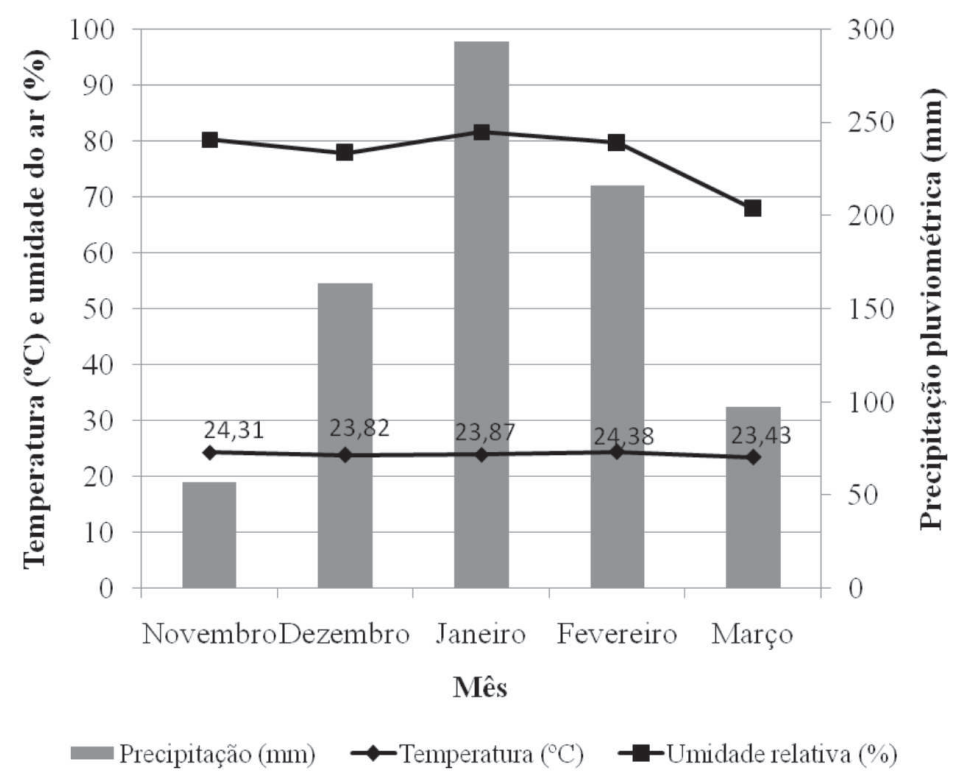

Figura 1. Médias de temperatura e umidade relativa do ar, e precipitação pluviométrica registradas na estação do INMET durante o período de 19/12/2009 a 16/03/2010, no município de Dois Vizinhos, PR, 2010. 
A calda bordalesa, em função de ter controlado a ferrugem e, consequentemente, ter mantido as folhas fotossinteticamente ativas por maior tempo, permitiu a produção de frutos com maior teor de sólidos solúveis totais (SST) e menor acidez total titulável (ATT) (Tabela 2), ou seja, frutos com maior relação SST/ATT (maior qualidade). Mullins et al. (1994) descreveram que o acúmulo de SST nas bagas de videira é dependente da fotossíntese e da importação de sacarose das folhas, a qual é posteriormente hidrolisada em glicose e frutose. A descrição, do autor supracitado, da relação fonte-dreno da videira não difere do que normalmente ocorre com a maioria das espécies frutíferas, incluindo a figueira. As plantas que receberam o tratamento com Amistar produziram frutos com teor intermediário de SST, entre o tratamento com calda bordalesa e o tratamento testemunha, sendo, esse último, o que apresentou o menor teor.

Apesar de o uso de calda bordalesa não ser, atualmente, uma inovação tecnológica para controle da ferrugem, a qual vem sendo utilizada há muitos anos para esse propósito, a sua boa eficiência de controle da ferrugem, também comprovada neste trabalho, é uma informação de grande importância para os produtores de figo da região, que carecem de conhecimento técnico para o controle fitossanitário dessa importante doença, sobretudo no sistema de produção agroecológica, frente às condições de mudanças climáticas, de regimes elevados de temperatura do ar e de precipitação pluviométrica, os quais aumentam as taxas de progresso da doença.

\section{Controle da broca-dos-ramos}

Observou-se influência dos diversos produtos testados sobre os componentes de rendimento das plantas (frutos/ramo, frutos/planta e produtividade) (Tabela 3).

O melhor controle da broca-dos-ramos, na primeira avaliação, foi obtido com a deltametrina, não se observando incidência da praga nos ramos sob esse tratamento, seguido do controle com extrato de alho, sem diferença estatística entre eles, os quais diferiram estatisticamente dos demais tratamentos (Tabela 3 ).

O extrato de alho, Allium sativum L. apresenta ação inseticida de largo espectro, com baixa seletividade em favor dos inimigos naturais, o que limita seu uso (Olkowski, 1995). Como inseticida é utilizado contra pulgões, lagartas, mosca-dos-chifres e pulgas, sendo também usado como carrapaticida (Prakash \& Rao, 1997). O inseticida biológico à base de rotenona (Rotenate CE) apresenta amplo espectro de ação por contato e ingestão, mas decompõe-se rapidamente pela ação da luz e calor, apresentando curto período residual. É usado no controle de besouros que se alimentam de folhas e frutos, vaquinha (Diabrotica speciosa, Germar, 1824) (Coleoptera: Chrysomelidae), lagartas, tripes, piolhos, mosquitos, pulgões, ácaros, carrapatos, pulgas, moscas e formiga lava-pé (Wiesbrook, 2004; Kathrina \& Antonio, 2004). De acordo com Guerra (1985), o sabão é mais efetivo quando acrescentado com outros produtos naturais de atividade inseticida, provavelmente por quebrar a tensão superficial da cutícula dos insetos, facilitando a ação de outros inse-

Tabela 2. Rendimento de frutos, severidade da ferrugem nas folhas, teores de sólidos solúveis totais (SST) e acidez total titulável (ATT) em figueira 'Roxo de Valinhos' em função da aplicação de fungicidas

\begin{tabular}{|c|c|c|c|c|c|}
\hline Tratamento & Ramos/planta & \multicolumn{2}{|c|}{ Frutos/ramo } & Frutos/planta & $\begin{array}{l}\text { Massa fresca } \\
\text { dos frutos (g) }\end{array}$ \\
\hline Calda Bordalesa & $44,88 \mathrm{a}$ & \multicolumn{2}{|c|}{$16,47 \mathrm{a}$} & $748 \mathrm{a}$ & $64,11 \mathrm{a}$ \\
\hline Azoxistrobin & $41,63 \mathrm{a}$ & \multicolumn{2}{|c|}{$16,03 \mathrm{a}$} & $676 \mathrm{a}$ & $55,46 \mathrm{~b}$ \\
\hline Testemunha & $43,50 \mathrm{a}$ & \multicolumn{2}{|c|}{$11,69 \mathrm{~b}$} & $528 \mathrm{a}$ & $47,68 \mathrm{c}$ \\
\hline Média & 43,33 & \multicolumn{2}{|c|}{14,73} & 650,63 & 55,75 \\
\hline $\mathrm{CV}(\%)$ & 9,75 & \multicolumn{2}{|c|}{15,39} & 24,08 & 1,10 \\
\hline $\mathrm{Pr}>\mathrm{F}$ & 0,580 & \multicolumn{2}{|c|}{0,045} & 0,211 & $<0,0001$ \\
\hline Tratamento & $\begin{array}{c}\text { Produtiv. } \\
\text { (kg/planta) }\end{array}$ & $\begin{array}{c}\text { Severidade }^{1} \\
\text { ferrugem }\end{array}$ & $\begin{array}{c}\text { Severidade }^{2} \\
\text { ferrugem }\end{array}$ & $\begin{array}{c}\text { SST } \\
\left({ }^{\circ} \text { Brix }\right)\end{array}$ & ATT(\%) \\
\hline Calda Bordalesa & $47,97 \mathrm{a}$ & $2,12 \mathrm{c}$ & $3,85 \mathrm{c}$ & $16,20 \mathrm{a}$ & $0,30 \mathrm{~b}$ \\
\hline Azoxistrobin & $37,53 \mathrm{ab}$ & $2,39 \mathrm{~b}$ & $4,35 \mathrm{~b}$ & $12,23 \mathrm{~b}$ & $0,41 \mathrm{a}$ \\
\hline Testemunha & $25,33 b$ & $3,11 \mathrm{a}$ & $5,66 \mathrm{a}$ & $10,76 \mathrm{c}$ & $0,34 \mathrm{~b}$ \\
\hline Média & 36,94 & 2,54 & 4,62 & 13,06 & 0,35 \\
\hline$\overline{\mathrm{CV}(\%)}$ & 21,19 & 4,34 & 4,34 & 3,76 & 7,88 \\
\hline $\mathrm{Pr}>\mathrm{F}$ & 0,018 & $<0,0001$ & $<0,0001$ & $<0,0001$ & 0,003 \\
\hline
\end{tabular}

Médias seguidas da mesma letra na coluna não diferem estatisticamente pelo teste de Tukey a $5 \%$ de probabilidade. ${ }^{1,2}$ Determinadas mediante escala diagramática (Lorenzetti et al., 2008) em 26/01 e em 28/02, respectivamente, sendo 1: sem sintomas; 2: até 4,39\% de lesão; 3: 4,39 a 8,88\%; 4: 8,88 a $16,00 \% ; 5$ : 16,00 a 33,32\%; 6: 33,32 a 63,00\%.

Rev. Ceres, Viçosa, v. 62, n.1, p. 044-051, jan/fev, 2015 
ticidas naturais. Esse pode ter sido o motivo para a baixa eficiência da calda de sabão no controle dessa praga. A azadiractina é um princípio ativo de amplo espectro de ação, que causa inibição de crescimento e altera a metamorfose de larvas de Lepidoptera, Coleoptera, Hymenoptera e Diptera, e ninfas de Orthoptera. Atua como antialimentar, principalmente em adultos de Coleoptera, Hemiptera e Orthoptera. É também repelente ou deterrente de oviposição e regulador de crescimento, em diferentes ordens de insetos (Martinez, 2002). A nicotina é um alcaloide neurotóxico, que vem sendo utilizado como fumigante, em casa de vegetação, e apresenta ação de contato, quando pulverizado contra insetos sugadores, especialmente insetos de corpo mole, como pulgões, mosca branca, cigarrinhas, tripes e ácaros (Kathrina \& Antonio, 2004; Wiesbrook, 2004).

Na segunda avaliação, os resultados foram semelhantes, entretanto, com infestações mais intensas da broca. A deltametrina foi o ingrediente ativo mais efetivo, no controle da broca (dano zero), diferindo estatisticamente do extrato de alho, o qual também diferiu dos demais tratamentos (Tabela 3). Assim, o extrato de alho, apesar de ter apresentado menor controle da broca do que o da deltametrina, tem potencial de ser empregado como inseticida biológico para o controle dessa importante praga da figueira, em sistema agroecológico de produção, associado com outras medidas de manejo integrado de controle, conforme sugerem Gallo et al. (2002) e Medeiros (2002), pois apresentou resultado satisfatório, superior ao dos demais tratamentos alternativos. No entanto, novos estudos com esse ingrediente ativo, principalmente, sobre a concentração a ser utilizada e do intervalo de aplicações, precisam ser realizados para a comprovação da sua eficiência no controle dessa praga, na figueira, sob distintas condições ambientais e de pressão da praga na cultura.

Em relação à produtividade de figos, os tratamentos com rotenona, sabão e nicotina, que apresentaram altos índices de ramos danificados pela broca, proporcionaram as maiores estimativas, diferindo estatisticamente dos demais tratamentos. Contrariamente, a deltametrina, que foi altamente eficiente no controle da broca, não foi o tratamento que promoveu a maior

Tabela 3. Rendimento de frutos e incidência de ramos danificados pela broca-dos-ramos na figueira 'Roxo de Valinhos' em função da aplicação de diferentes inseticidas naturais

\begin{tabular}{|c|c|c|c|c|}
\hline Tratamento * & Ramos/planta & Frutos/ramo & Frutos/planta & Peso médio frutos $(\mathrm{g})$ \\
\hline Azadiractina & $27,75 \mathrm{~ns}$ & $8,63 \mathrm{~b}$ & $239 b$ & $48,60 \mathrm{~ns}$ \\
\hline Alho & 30,00 & $9,53 \mathrm{~b}$ & $303 b$ & 48,12 \\
\hline Cinza & 31,7 & $9,44 \mathrm{~b}$ & $290 b$ & 41,68 \\
\hline Nicotina & 30,00 & $12,59 \mathrm{a}$ & $375 a$ & 48,24 \\
\hline Deltametrina & 28,50 & $8,78 \mathrm{~b}$ & $264 b$ & 49,36 \\
\hline B. thuringiensis & 33,25 & $7,47 \mathrm{~b}$ & $256 b$ & 48,34 \\
\hline Rotenona & 34,75 & $12,75 \mathrm{a}$ & $448 \mathrm{a}$ & 47,28 \\
\hline Sabão de coco & 27,50 & $15,31 \mathrm{a}$ & $407 \mathrm{a}$ & 50,18 \\
\hline Testemunha $\left(\mathrm{H}_{2} \mathrm{O}\right)$ & 28,75 & $9,28 \mathrm{~b}$ & $260 \mathrm{~b}$ & 56,26 \\
\hline Média & 30,25 & 10,42 & 315,81 & 48,67 \\
\hline $\mathrm{CV}(\%)$ & 17,96 & 27,81 & 30,77 & 14,42 \\
\hline $\operatorname{Pr}>F$ & 0,067 & 0,015 & 0,046 & 0,377 \\
\hline Tratamento * & \multicolumn{2}{|c|}{ Produtividade (kg/planta) } & $\operatorname{icados}^{1}(\%)$ & $\operatorname{Ramos}$ danificados ${ }^{2}(\%)$ \\
\hline Azadiractina & \multicolumn{2}{|c|}{$11,68 b$} & & $40,63 \mathrm{a}$ \\
\hline Alho & \multicolumn{2}{|c|}{$14,37 \mathrm{~b}$} & & $18,75 b$ \\
\hline Cinza & \multicolumn{2}{|c|}{$11,34 \mathrm{~b}$} & & $37,50 \mathrm{a}$ \\
\hline Nicotina & \multicolumn{2}{|c|}{$18,13 \mathrm{a}$} & & $28,13 \mathrm{a}$ \\
\hline Deltametrina & \multicolumn{2}{|c|}{$13,05 \mathrm{~b}$} & & $0,00 \mathrm{c}$ \\
\hline B. thuringiensis & \multicolumn{2}{|c|}{$12,45 \mathrm{~b}$} & & $34,38 \mathrm{a}$ \\
\hline Rotenona & \multicolumn{2}{|c|}{$21,20 \mathrm{a}$} & & $59,38 \mathrm{a}$ \\
\hline Sabão de coco & \multicolumn{2}{|c|}{$20,34 \mathrm{a}$} & & $53,13 \mathrm{a}$ \\
\hline Testemunha $\left(\mathrm{H}_{2} \mathrm{O}\right)$ & \multicolumn{2}{|c|}{$14,69 b$} & & $50,00 \mathrm{a}$ \\
\hline Média & \multicolumn{2}{|c|}{15,25} & & 35,76 \\
\hline $\mathrm{CV}(\%)$ & \multicolumn{2}{|c|}{26,15} & & 25,19 \\
\hline $\mathrm{Pr}>\mathrm{F}$ & \multicolumn{2}{|c|}{0,008} & & $<0,0001$ \\
\hline
\end{tabular}

* Médias seguidas da mesma letra na coluna não diferem estatisticamente pelo teste de Scott-Knott a 5\% de probabilidade. ${ }^{1,2}$ Avaliações realizadas em 22/01 e em 22/02, respectivamente. 
produtividade de frutos por planta (Tabela 3). Esses resultados diferem dos de Fadini et al. (2003), que observaram, em Minas Gerais, que o aumento da percentagem de ramos broqueados afetou o peso e o número de frutos produzidos e, consequentemente, a produtividade das plantas. As diferenças estatísticas para número de frutos por ramo, frutos por planta e produtividade (kg/planta) desses mesmos tratamentos, em relação aos dos demais (Tabela 3), possivelmente, sejam devidas ao padrão de crescimento (vigor) diferencial entre as plantas dos diferentes tratamentos, graças a fatores nutricionais e, ou, ambientais, não controlados nesta pesquisa.

Verificou-se, neste trabalho, que a maior parte da emissão de frutos ocorreu em curto espaço de tempo, anterior ao período de maior ocorrência da broca (dados não mostrados). Dessa forma, acredita-se que a produção comercial da safra sob análise, em termos de número de frutos por ramo e por planta, já estava previamente definida, em relação ao período de maior incidência de broca-dos-ramos. Assim, o adequado controle fitossanitário da ferrugem é o fator mais importante a garantir boa produtividade e qualidade dos frutos (Tabela 2). Na região de Valinhos-SP, a colheita dos frutos para mercado estende-se de novembro a maio, concentrando-se entre dezembro e março (Corrêa \& Santos, 1999). Na região de Passo Fundo, RS, a produção de frutos maduros inicia-se tardiamente, no final de janeiro ou início de fevereiro, estendendo-se até abril ou início de maio (Nienow et al., 2006). Segundo Fadini et al. (2003), a maior ocorrência de A. gripusalis, em Minas Gerais, foi observada entre 19 de dezembro e 15 de maio do ano subsequente, correspondendo, nesse período, a $95,4 \%$ do total de indivíduos coletados, sendo que o maior pico populacional ocorreu em março. A partir de maio, a população de A. gripusalis reduziu-se bruscamente.

As condições meteorológicas da região, de alta umidade e, sobretudo, de elevada temperatura do ar, principalmente de dezembro de 2009 a fevereiro de 2010 (Figura 1), mostraram-se muito favoráveis ao desenvolvimento da ferrugem e da broca-dos-ramos. A temperatura é o fator de maior influência no aumento populacional da broca-dos-ramos da figueira (Fadini et al., 2003), afetando também o desenvolvimento da ferrugem a campo (Medeiros, 2002). Por outro lado, Fadini et al. (2003) não observaram correlação positiva entre os índices de umidade do ar e de precipitação pluviométrica, no aumento populacional dessa praga. No entanto, as chuvas ocorridas após a aplicação dos produtos podem ter contribuído para a redução da eficiência dos produtos usados para controle da ferrugem e da broca-dos-ramos, por causa da remoção dos produtos da superfície foliar.

\section{CONCLUSÕES}

A calda bordalesa na concentração de $1,5 \mathrm{~kg} / 100 \mathrm{~L}$ foi o tratamento mais efetivo no controle da ferrugem, promovendo aumento da produtividade e da qualidade dos frutos, em relação à massa fresca e ao teor de sólidos solúveis.

$\mathrm{O}$ ingrediente ativo que promoveu o melhor controle da broca-dos-ramos foi a deltametrina. $\mathrm{O}$ extrato de alho foi superior aos demais tratamentos alternativos no controle dessa praga.

\section{REFERÊNCIAS}

Abrahão E, Alvarenga AA, Fragoas JC \& Silva VJ (2002) A cultura da figueira (Ficus carica L.) na região de Lavras, MG - Situação atual e perspectivas. Ciência e Agrotecnologia, 26:643-647.

Alves G (2006) Avaliação de danos causados pela ferrugem em pomar de pessegueiro da cultivar chimarrita. Dissertação de Mestrado. Universidade Federal do Paraná, Curitiba. 71p.

Bernardes MS (1987) Fotossíntese no dossel das plantas cultivadas. In: Castro PRC, Ferreira SO \& Yamada T (Eds.) Ecofisiologia da produção agrícola. Piracicaba, Associação brasileira para pesquisa da potassa e do fosfato. p.13-45.

Corrêa LS \& Santos SC (1999) Condução e tratos culturais da figueira. In: Corrêa LS \& Boliani AC (Eds.) Cultura da figueira: do plantio à comercialização. Ilha Solteira, FUNEP/FAPESP. p.51-68.

Carvalho WP (2009) Uso de caldas e biofertilizante no controle da ferrugem asiática da soja em sistema orgânico no Distrito Federal. In: $6^{\circ}$ Congresso Brasileiro de Agroecologia e $2^{\circ}$ Congresso Latino Americano de Agroecologia, Curitiba. Anais, SBA. p.52-56.

Chalfoun SM \& Carvalho VL (1997) Doenças da figueira. Informe Agropecuário, 18:39-42.

Cruz CD (2006) Programa Genes: estatística experimental e matrizes. Viçosa, Universidade Federal de Viçosa. 285p.

Dalastra IM, Pio R, Campagnolo MA, Dalastra GM, Chagas EA \& Guimarães VF (2009) Épocas de poda na produção de figos verdes 'Roxo de Valinhos' em sistema orgânico na região Oeste do Paraná. Revista Brasileira de Fruticultura, 31:447-453.

Embrapa - Centro Nacional de Pesquisa de Solos (CNPS) (2006) Sistema Brasileiro de Classificação de Solos. 2aed. Rio de Janeiro, Embrapa Solos. 412p.

Fadini MAM, Filho JD \& Antunes LEC (2003) Danos causados pela broca da figueira na produção de frutos e flutuação populacional dos adultos. Pesquisa Agropecuária Brasileira, 38:1209-1215.

Freire FCO, Parente GB \& Cardoso BB (2006) Doenças da figueira (Ficus carica L.) no Estado do Ceará. Fortaleza, Embrapa Agroindústria Tropical. 5p. (Circular técnica, 26).

Gallo D, Nakano O, Silveria Neto S, Carvalho RPL, Baptista GC, Berti Filho E, Parra JPP, Zuchi RA, Alves SB, Vendramim JD, Marchini LC, Lopes JRS \& Omoto C (2002) Entomologia agrícola. Piracicaba, Esalq. 920p.

Giacobbo CL, Picolotto L, Krueger LR, Parizotto E, Tibola C \& Fachinello JC (2007) Cultivo da figueira conduzida em quatro diferentes densidades de plantio. Revista Brasileira de Agrociência, 13:43-46.

Goes A, Martins RD \& Reis RF (2004) Efeito de fungicidas cúpricos, aplicados isoladamente ou em combinação com mancozeb, na expressão de sintomas de fitotoxicidade e controle da ferrugem causada por Puccinia psidii em goiabeira. Revista Brasileira de Fruticultura, 26:237-240. 
Guerra MS (1985) Receituário caseiro: alternativas para o controle de pragas e doenças de plantas cultivadas e seus produtos. Brasília EMBRATER. 166p.

Ibge/Sidra (2015) Sistema IBGE de Recuperação Automática-SIDRA Disponível em: < http://www.sidra.ibge.gov.br/bda>. Acessado em: 09 de fevereiro de 2015.

Inmet (2010) Estação meteorológica A843 de Dois Vizinhos, PR. Disponível em: <http://www.inmet.gov.br/sonabra/sonabra.html>. Acessado em: 20 de março de 2010.

Jackson JE (1980) Light interception and utilization by orchard systems. Horticultural Reviews, 2:208-267.

Kathrina GA \& Antonio LOJ (2004) Controle biológico de insectos mediante extractos botánicos. In: Carball M \& Guaharay F (Eds.) Control biologico de plagas agrícolas. Managua, CATIE. p.137-160. (Serie Técnica. Manual Técnico/CATIE, 53).

Köppen W (1936) Das geographische system der klimate. In: Köppen W \& Geiger R (Eds.) Handbuch der klimatologie. Berlin, Gebrüder Bornträger. p.1-44.

Lorenzetti ER, Porcena AS \& Conceição DM (2008) Escala diagramática para avaliação da severidade de ferrugem do figo causada por Cerotelium fici (Cast.). In: $20^{\circ}$ Congresso Brasileiro de Fruticultura, Vitória. Anais, SBF. CD-ROM.
Martinez SS (2002) O nim, Azadiractina indica - Natureza, usos múltiplos, produção. Londrina, IAPAR. 142p.

Medeiros ARM (2002) Figueira (Ficus carica L.) do plantio ao processamento caseiro. Pelotas, Embrapa Clima Temperado. 16p. (Circular Técnica, 35).

Mullins MG, Bouquet A \& Willians LE (1994) Biology of the grapevine. New York, University of Cambridge. 239p.

Nienow AA, Chaves A, Lajús CR \& Calvete EO (2006) Produção da figueira em ambiente protegido submetida a diferentes épocas de poda e número de ramos. Revista Brasileira de Fruticultura, 28:421424.

Olkowski W, Daar S \& Olkowski H (1995) The organic gardener's handbook of natural insect and disease control. Emmaus, Rodale Press Inc. 544p.

Pio R, Chagas EA, Campo Dall'orto FA \& Barbosa W (2007) Manejo para o cultivo da figueira. Campo \& Negócio, Uberlândia. p.62-63.

Prakash A \& Rao J (1997) Botanical pesticides in agriculture. USA, CRC. 461p.

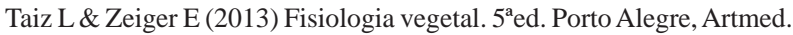
954p.

Wiesbrook ML (2004) Natural indeed: Are natural insecticides safer and better than conventional insecticides? Illinois Pesticide Review, 17:01-08. 